\title{
Genetic testing for respiratory disease: Are we there yet?
}

\author{
Peter D Paré MD, Editor-in-Chief
}

\begin{abstract}
P Pare. Genetic testing for respiratory disease: Are we there yet? Can Respir J 2012;19(4):246-248.

The human genome project promised a revolution in health care - the development of 'personalized medicine', where knowledge of an individual's genetic code enables the prediction of risk for specific diseases and the potential to alter that risk based on preventive measures and lifestyle modification. The present brief review provides a report card on the progress toward that goal with respect to respiratory disease. Should generalized population screening for genetic risk factors for respiratory disease be instituted? Or not?
\end{abstract}

Key Words: Asthma; Cystic fibrosis; COPD; Genetics; Human genome project; Screening

The term 'personalized medicine' has a comforting ring to it! It 1 invokes an image of health care customized for the individual; a tailoring of preventive measures and treatments to their particular needs. However, the term has recently become synonymous with the use of individual genetic information to guide the tailoring of prevention and treatment. That we can even consider this possibility is because of the remarkable advances in technology that spawned the human genome project.

The human genome project was started in 1990 and, at a cost of approximately \$US3 billion, a description of the entire nucleotide sequence for the approximately 25,000 genes that are needed to design a human being was completed in 2003 . The project and subsequent study of the variation in the human genome showed that we are all the same... and all different! More than $99 \%$ of the DNA code between individuals is identical. However, it is the variation in the remaining $1 \%$ that gives us our individuality, including our individual risks for disease and our individual responses to drugs and environmental factors.

All human disease occurs because of an interaction between our genes and the environment, but the relative contribution of each varies widely, from single-gene Mendelian disorders in which a single mutation (polymorphism) is sufficient to produce the disease (eg, cystic fibrosis [CF]) to complex genetic diseases in which multiple polymorphisms in susceptibility genes combined with environmental exposures are needed for disease expression (eg, chronic obstructive pulmonary diease [COPD]) (Figure 1).

The proponents of the human genome project 'sold it' with promises of a revolution in health care. The 'promise' was that knowledge of the variation in an individual's genes would enable prediction of risk for particular diseases and help the individual and their caregivers to select the best lifestyle choices to prevent the disorders as well as prescribe the best medication to achieve the maximal benefit with minimal side effects.

Has the human genome project delivered? The answer is yes...and no. The idea that you will be able to survey your genes to predict your risk of disease and suggest lifestyle modification is still a pipedream and may never be achieved; however, in selected instances, genetic testing is influencing the diagnosis and management of patients with pulmonary diseases.

\section{Les tests génétiques des maladies respiratoires : sommes-nous rendus là?}

Le projet du génome humain promettait une révolution des soins de santé par l'avènement d'une " médecine personnalisée ». On croyait que le fait de connaître le code génétique d'un individu permettrait de prédire le risque de maladies précises et qu'on pourrait réduire ce risque grâce à des mesures préventives et à des modifications au mode de vie. La présente courte analyse fournit un bulletin des progrès réalisés vers l'atteinte de cet objectif dans le secteur des maladies respiratoires. Devrait-on adopter le dépistage généralisé en population pour déterminer les facteurs de risque génétiques de maladie respiratoire ou non?

The usefulness of genetic screening for disease risk is dependent on the following: the degree of risk contributed by genetics; the sensitivity and specificity of the test; and the implications of a positive or negative test. For the relatively rare single-gene disorders, such as $\mathrm{CF}$, a single gene mutation is all that is needed to cause the disease; therefore, the sensitivity and specificity of genetic screening is near $100 \%$. However, even when a test is $100 \%$ sensitive and specific, one would question its use in screening if there were no preventive or therapeutic interventions that could be applied. Until recently, there was little reason to screen for $\mathrm{CF}$ mutations because there were no specific preventive or therapeutic interventions that could be instituted based on genotype. However, the report that a new drug, ivacaftor, corrects sweat chloride levels and improves lung function in the approximately $5 \%$ of $\mathrm{CF}$ patients who carry this mutation, means that important therapeutic decisions will now be based on genotype in CF (1). It is hoped that additional specific therapies that target other CF mutations will soon be developed. A future issue of the Canadian Respiratory Journal will publish a review article concerning these exciting new developments.

The genetic contribution to complex pulmonary diseases, such as asthma and COPD, is less. Inheriting the susceptibility genes containing the polymorphisms that increase risk is not enough to cause disease; specific environmental exposures interact with the susceptibility genes to cause disease. The predictive value of genetic screening in such conditions is poor. In fact, even if we tested all of the known genetic variants that have been shown to be associated with COPD or asthma, the sensitivity and specificity of prediction of risk for these disorders is still substantially lower than can be derived from taking a family history.

For example, results from one large study involving 25,000 individuals (2) recently showed that a polymorphism in one gene (ORMDL) was significantly related to increased risk for asthma. Although it was highly significant, it was not a powerful predictor of individual risk. Having the mutation meant that you had an approximately one in nine chance of having asthma symptoms at some time during your life (ie, 11\%); however, the risk for individuals without this mutation is one in $10(10 \%)$. The difference between an $11 \%$ and $10 \%$ risk was highly significant in a study involving thousands of individuals; however, for predicting individual risk, it is not meaningful. Even if the

University of British Columbia, James Hogg Research Centre, St Paul's Hospital, Vancouver, British Columbia

Correspondence: Dr Peter D Paré, St Paul's Hospital, 1081 Burrard Street, Vancouver, British Columbia V6Z 1 Y6.

E-mail Peter.Pare@hli.ubc.ca 
prediction of risk was more powerful, we still do not know how to prevent asthma in susceptible individuals. If you knew your risk was slightly increased $(11 \%$ instead of $10 \%)$ what could you do about it? We do not know. You definitely would not smoke; however, there are so many other reasons not to smoke that this slight difference in risk would not likely sway you. Exposure to allergens contributes to asthma, so you might try to avoid allergens, but allergens are all around us. You might not buy a cat, but you will be exposed to pollen during the spring. Short of moving to Antarctica, there is no way of avoiding all allergens.

There are some common diseases for which we have more precise knowledge of the environmental risk factors and the capacity to alter them, for example, COPD as well as atherosclerosis. We know that smoking, lack of exercise, a fatty western diet, high blood pressure and obesity are some of the important environmental risk factors that interact with the genes that increase the risk for COPD and atherosclerosis. So why not screen people for the risk polymorphisms and, if they are carriers, suggest they quit smoking, exercise more, eat less fat, lower their blood pressure and lose weight? But what about those who do not carry the risk genes? Can they smoke, exercise less, eat fat, let their blood pressure rise and safely become obese? No. Even in the absence of risk genes, these lifestyle choices are bad for you. Enough of these environmental factors will cause COPD and heart disease even in those without genetic risk factors.

On the other hand, the discovery that polymorphisms in specific genes increase risk for these common diseases has substantially increased our knowledge of how these diseases originate and may lead to new therapies for them. For example, the study of the genetics of asthma mentioned above showed that many of the genes that predispose to asthma are expressed in airway epithelial cells, not in inflammatory/ immune cells. This knowledge has led to a whole new take on the origin of asthma. Although it is clear that an altered immune response to common environmental allergens is a key component of allergic asthma, the genetic studies suggest that the altered response may be initiated by a primary dysfunction of the airway epithelium and how it responds to inhaled substances. It is important to realize that although the polymorphisms in these genes increase risk in only a minority of individuals who have asthma, the genetic studies have identified pathways that are important in all who suffer from this disorder.

Although we are not ready for population screening for common complex diseases, this has not stopped the development of direct-toconsumer genetic screening. There are a number of for-profit companies to whom you can send your DNA and have it screened for all of the published risk genes. One such company is ' 23 and Me' (www.23andme.com).

A couple of years ago, they were offering to perform a complete genetic screen for $\$ 500$, but recently, the price has come down dramatically. When a 'holiday special' - a complete gene screen for $\$ 99$ - was offered, I could not resist. I requested a kit online and, in a few days, a package arrived complete with a mouth wash liquid that I swished around before returning it to them. Within a few weeks, my results were available online, password protected, of course. In addition to giving you your chances of succumbing to different diseases, the genetic screening provides you with some information regarding ancestry. I thought I knew my complete ancestry: one grandparent from Ireland, one from Scotland, one from Australia and one from France via Quebec. I was somewhat surprised to find that my maternal DNA matched best with DNA from northern Scandinavia. My only conclusion is that my great, great, great grandmother must have been a Viking!

What did I learn about my risk for disease? Well, my chance of macular degeneration is $5.3 \%$ versus a population risk of $7 \%$. But my risk for colon cancer is $6.8 \%$ versus a population risk of $5.6 \%$. Not much different, and little I can do about it even if the risk was higher. There was some useful information: I learned that I am more sensitive to the anticoagulant warfarin than the average person, so if I ever need this treatment, I can tell my physician to start with a low dose.

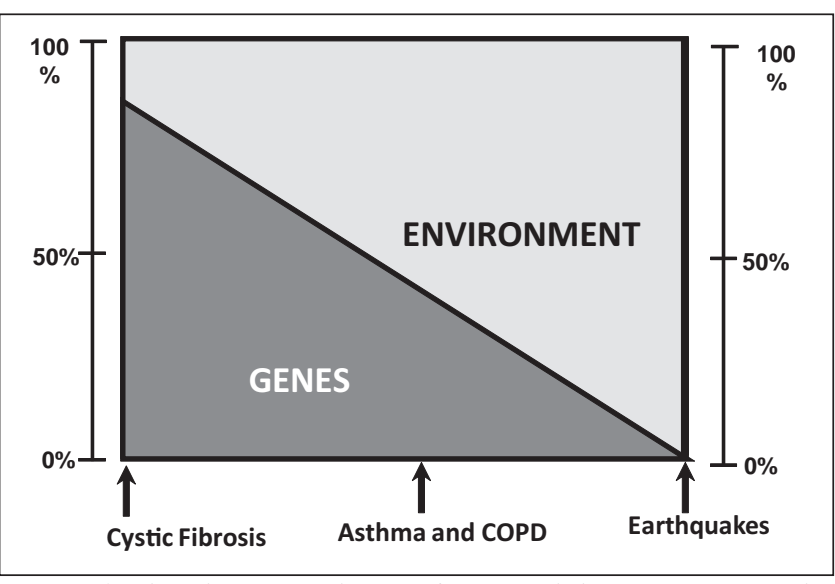

Figure 1) The relative contribution of genes and the environment to disease. On one end of the spectrum, cystic fibrosis is mainly genetic, although the environment, in the form of intensive medical therapy with antibiotics, enzymes and physiotherapy, can alter the course of the disease. On the other end of the spectrum, genetics has nothing to do with death from earthquakes! The vast majority of common human diseases, including asthma and chronic obstructive pulmonary disease (COPD), involve a combination of genetic risk factors that interact with environmental factors to cause disease

Ominously, there were some reports on the website called "locked reports"; they came with a warning: "Before you click on this site you should know that you are about to find out if you have some quite rare gene variants that substantially increase your chances of Parkinson's disease, breast cancer, Alzheimer's". This causes a dilemma. These rare mutations are more like the mutation that causes CF. Although they do not predict $100 \%$ that you will get the disease, they do have a much higher predictive value (approximately 20\%). However, these mutations are quite rare, so the odds are that by clicking on the button you will find you don't have the gene and so you can relax. But what if you do have it? To click or not to click? Because there is little that can be done to prevent the onset of Parkinson's or Alzheimer's disease, it was a 'no-brainer' for me. I did not click those buttons but others might take the chance.

The button that provided an estimation of breast cancer risk was potentially a bigger ethical dilemma. Although I have a very low chance of getting breast cancer, being a male, this test could tell me if I am a carrier of the rare but highly predictive breast cancer risk gene. If I am a carrier, I could pass the polymorphic gene on to my daughters and granddaughters. What if I clicked and found that I was a carrier? Do I tell my daughters and granddaughters I'm positive? Should I then advise them to get tested? You can appreciate the moral dilemmas that this indiscriminate genetic testing could generate.

A major problem with this direct-to-consumer genetic testing is the anxiety it can cause due to lack of knowledge in the population about how to interpret the results. Our society does not have the capacity to deal with the genetic counselling that would be required if everyone were tested. The website states that you need to consult your physician if you are uncertain about a result. However, most physicians are unclear about how to interpret the results even if they had the time to explain their quite subtle implications.

How about the successes? Given the hype, there are relatively few. However, there have been some very practical and advantageous genetic discoveries, especially concerning genes that influence interindividual variations in our response to specific drugs. As mentioned above, there are two gene polymorphisms that influence how sensitive one will be to blood thinners. It is now recommended that your starting dose be adjusted according to your genetic profile for two specific genes (3). 
The biggest successes have been in the selection of treatment for certain cancers (4). The genetic testing in these instances is for new mutations that have developed in the cancer, not those that the patient has inherited. These mutations can dramatically affect how well a patient responds to specific chemotherapy. For example, lung cancers that develop mutations in the gene for the epidermal growth factor receptor (EGFR) often respond dramatically to an oral drug that inhibits the EGFR receptor (5). Such findings mean that patients can receive customized chemotherapy, thus maximizing the benefit. Similarly, those without the mutation can be treated with a different therapy and, thus, avoid any side effects associated with a drug that they are not likely to respond to.

In summary, we are not ready for mass population-based screening for genes that only slightly increase the risk of common diseases. The risk imparted by these genes is too small to enable us to make meaningful decisions and, in many cases, there is no known behavioural change that would alter the risk. In most cases, the predicted risk from gene testing is less than can be obtained by taking a careful family history. Moreover, even when we do know what environmental factors are involved, they are factors that should be avoided or embraced by everyone, not just those who have slightly increased risk.
On the plus side, there are an increasing number of genetic predictors of beneficial and adverse response to specific drugs. Thus, personalized medicine, although not the utopian scenario originally envisioned, is slowly having an increasing impact on how we practice medicine.

\section{REFERNECES}

1. Ramsey BW, Davies J, McElvaney NG, et al; VX08-770-102 Study Group. A CFTR potentiator in patients with cystic fibrosis and the G551D mutation. N Engl J Med 2011;365:1663-72.

2. Moffatt MF, Gut IG, Demenais F, et al; GABRIEL Consortium. A large-scale, consortium-based genomewide association study of asthma. N Engl J Med 2010;363:1211-21.

3. Oldenburg J, Bevans CG, Fregin A, Geisen C, Müller-Reible C, Watzka M. Current pharmacogenetic developments in oral anticoagulation therapy: The influence of variant VKORC1 and CYP2C9 alleles. Thromb Haemost 2007;98:570-8.

4. Cagle PT, Chirieac LR. Advances in treatment of lung cancer with targeted therapy. Arch Pathol Lab Med 2012;136:504-9.

5. Maemondo M, Inoue A, Kobayashi K, et al; North-East Japan Study Group. Gefitinib or chemotherapy for non-small-cell lung cancer with mutated EGFR. N Engl J Med 2010;362:2380-8. 


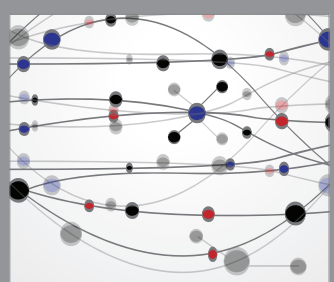

The Scientific World Journal
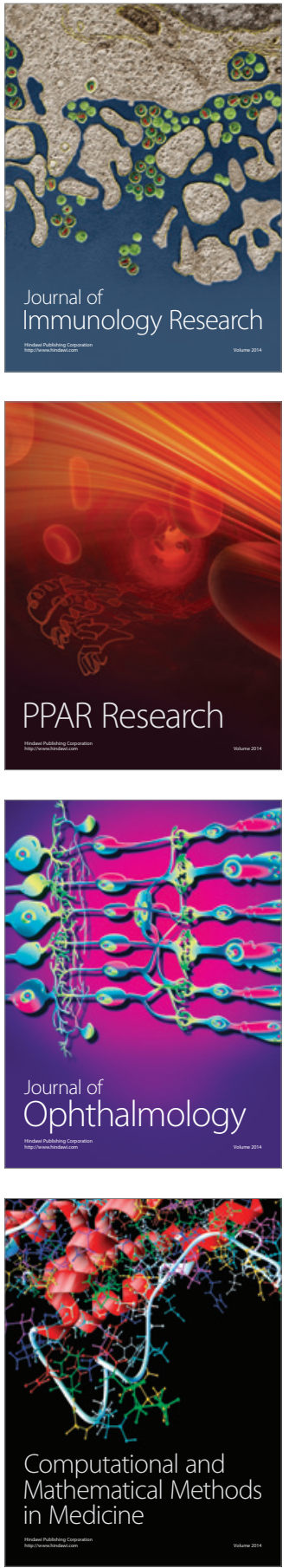

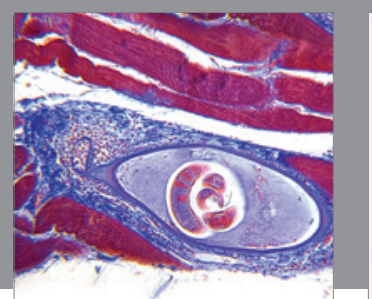

Gastroenterology Research and Practice

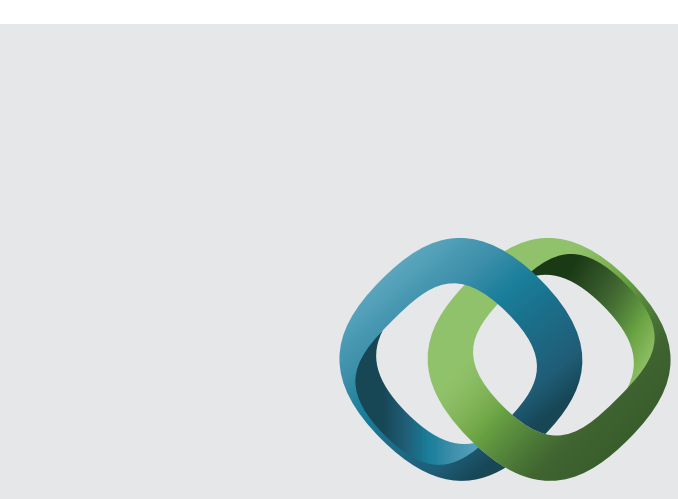

\section{Hindawi}

Submit your manuscripts at

http://www.hindawi.com
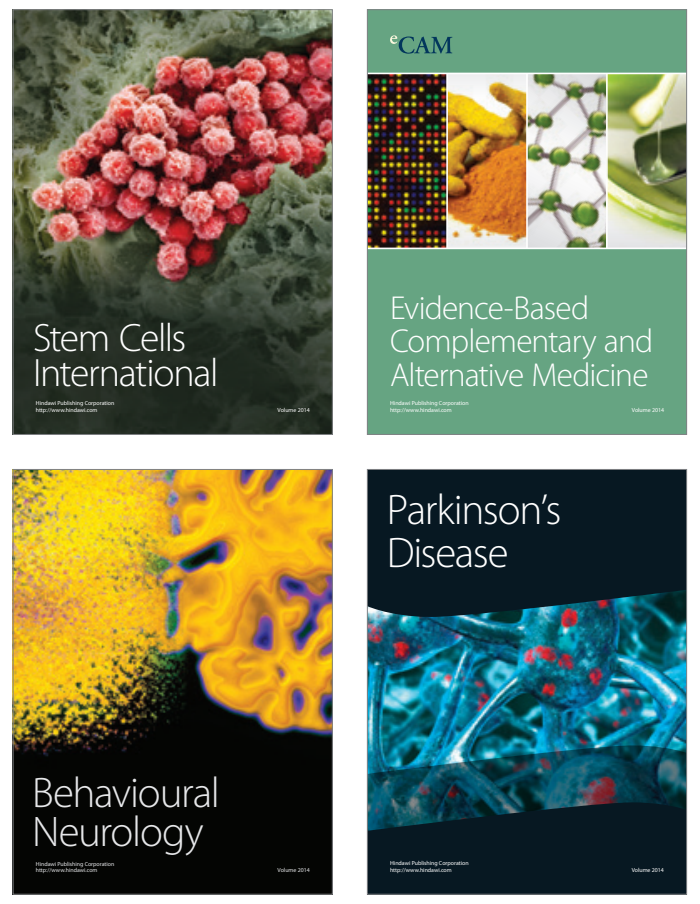
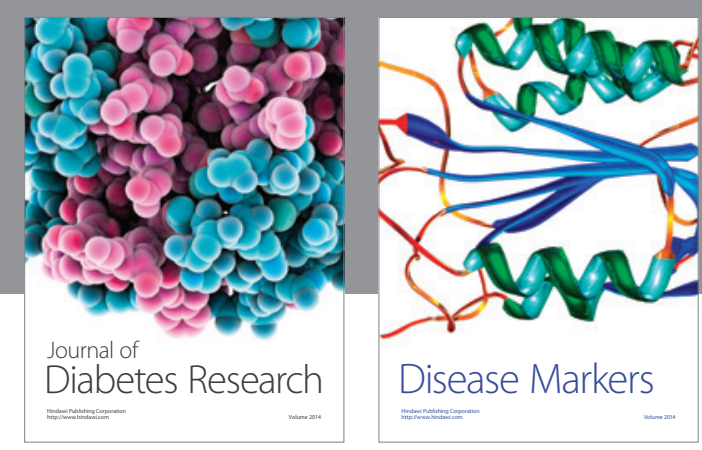

Disease Markers
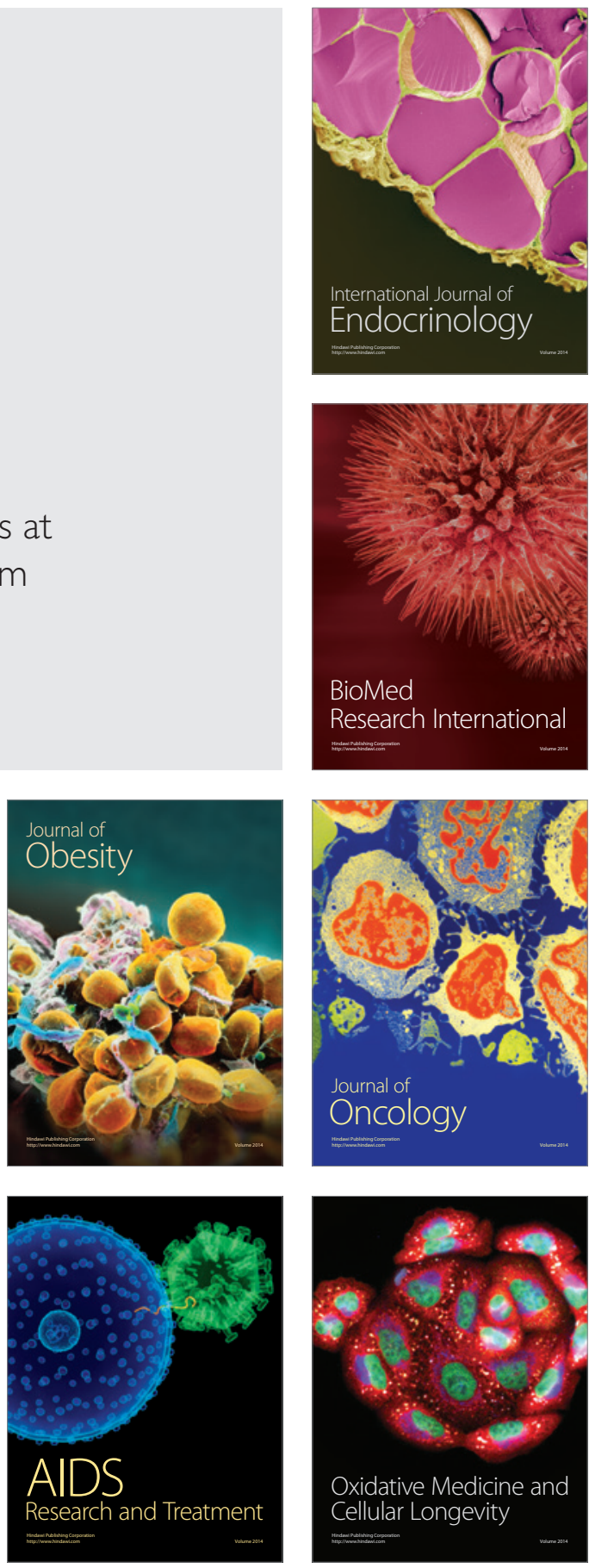